\title{
POLÍtTICAS PÚBLICAS E CONTROLE DE CONSTITUCIONALIDADE: APROXIMAÇÕES ENTRE A CIÊNCIA JURÍDICA E A CIÊNCIA POLÍTICA
}

Hector Cury Soares

\section{Resumo}

O presente artigo tem como objetivos centrais apresentar o modelo de controle de constitucionalidade adotado pela Constituição brasileira, bem como a origem desses modelos e os reflexos (ou possíveis) no controle da constitucionalidade das políticas públicas no Brasil. Da mesma forma, os possíveis limites que possam ser estabelecidos e os efeitos que, por ventura, possa ter esse controle, em relação às políticas públicas. Por conseguinte, estabelece-se uma linha que permite identificar os principais problemas da importação desses modelos e tracejar critérios que possam ser universalizáveis ao controle das políticas públicas no Brasil, carência evidenciada no Direito Administrativo e que demonstra uma lacuna entre o estudo das políticas públicas na ciência política e na ciência jurídica.

Palavras-chave: Controle de Constitucionalidade; Políticas Públicas; Administração Pública.

\begin{abstract}
This article aims to present the model of judicial review adopted by the Brazilian Constitution, as well as the origin of these models and reflections (or posibles) to judicial review of public policies in Brazil. Similarly, the possible limits that may be established and the effect that, perchance, to have this control, in relation to public policies.Therefore, establishing a line identifying the key problems of importation of these models and dashed criteria that may be universalizable the control of public policy in Brazil, grace evidenced in Administrative Law and that demonstrates a gap between the study of public policy in politics and jurisprudence.
\end{abstract}

Keywords: Judicial Review; Policies; Public Administration.

Não matou outros deuses O triste deus cristão.

Cristo é um deus a mais, Talvez um que faltava. (FERNANDO PESSOA, 2008, p. 37).

\section{Introdução}

Se, por um lado, a Constituição Federal de 1988 (CF) deu ao Supremo Tribunal Federal a condição de guarda da Constituição (HECK, 2008 e 2002), por outro criou uma série de instrumentos que possibilitassem o acesso ao mesmo. A tarefa de guarda da Constituição está regulada no art. 102, caput. Também regula o direito de petição na ação de inconstitucionalidade, a qual 
se encontra regulada no art. 102, I, CF. Além disso, por meio da Emenda Constitucional no 3 (EC), introduziu-se no ordenamento jurídico brasileiro a ação direta de inconstitucionalidade. Ainda com base na citada emenda, criouse a arguição de descumprimento de preceito fundamental, prevista no art. 102 , § $2^{\circ}$, da CF.

Enquanto a arguição de descumprimento de preceito fundamental foi regulada pela Lei 9.882 de 3 de dezembro de 1999, a ação direta de constitucionalidade e ação direta de inconstitucionalidade foram reguladas pela Lei $n^{\circ} 9.868$ de 10 de novembro de 1999. Essas ações tratam do controle quando a questão principal é inconstitucionalidade/ constitucionalidade da lei, que é objeto do procedimento. Contudo, não se esgotam aí as possibilidades de controle de constitucionalidade no Brasil, pois há ainda o chamado controle difuso. Nesse caso, há um litígio jurídico que tem como objeto a conformidade ao direito de um ato (HECK, 2002).

Portanto, a Constituição Federal de 1988 não deixa dúvida em relação à justiciabilidade dos direitos fundamentais, tendo em vista a eficácia dos direitos fundamentais sociais. Em que pese exista na doutrina jusconstitucionalista brasileira posições que afirmem a eficácia reduzida dos direitos fundamentais sociais, bem como a possibilidade de serem insuscetíveis de serem justiciabilizados, há, também, a sustentação que os direitos fundamentais sociais são direitos subjetivos. Contudo, esta última posição não oferece uma solução para problemas ligados à aplicação dos direitos fundamentais sociais. A despeito das duas perspectivas o texto constitucional dá margem para que se busque, pela via judicial, a aplicação de um direito fundamental social.

Ocorre que, por vezes, a resposta judicial reflete diretamente na organização da Administração Pública do Estado e nas políticas públicas propostas por determinado ente federativo não dando respostas em relação a recursos financeiros para a sua realização, os meios para o cumprimento, a competência do Legislativo e do Executivo para a definição do orçamento público e a formulação de políticas públicas. Todos esses pontos ficam em aberto, concedendo-se amplo poder discricionário ao Judiciário. Não se olvida que os direitos fundamentais sociais e sua eficácia devem ser base das políticas públicas, ou seja, na base de uma política pública está a aplicação de um direito fundamental social. A sua figura, no âmbito jurídico, surge como uma forma de concretização dos chamados direitos sociais, fruto de transformação do Estado liberal operada no século XX. Exigem-se prestações positivas do Estado com os chamados direitos sociais, apresentando-se no universo jurídico as políticas públicas.

No entanto, a intervenção do Poder Judiciário deve estar pautada por fundamentos (justificativas) que apresentem soluções entre a negação da eficácia aos direitos fundamentais sociais e, portanto, a impossibilidade de intervenção do Judiciário em políticas públicas e aqueles que consideram ser possível tudo em matéria de direitos fundamentais sociais. Essa base jurídica, como se pode observar, passa também por aspectos decisórios, de fundo político, na Administração Pública. Desta maneira, o agente público 
necessariamente goza de um poder discricional à sua escolha em se tratando de políticas públicas, sendo essa a contribuição dada pela ciência política. Para a ciência jurídica, não obstante, é preciso observar a conformidade da escolha com a Constituição Federal e, estando fora do preconizado pela Constituição caberia ao Judiciário intervir nas políticas públicas, mas de forma que utilizasse fundamentos a sua intervenção, ou seja, o Judiciário também deve justificar racional-argumentativamente (com base na Constituição Federal) a sua escolha em políticas públicas. Destarte, necessária uma aproximação entre as políticas públicas nas ciências política e jurídica, como forma de possibilitar um maior controle, na seara judicial, baseado na Constituição brasileira vigente em termos de políticas públicas.

Com isso intenta-se apresentar por meio de uma revisão bibliográfica dos principais conceitos ligados à relação entre controle de constitucionalidade e políticas públicas, apresentar os problemas decorrentes da importação de modelos estrangeiros de controle de constitucionalidade e seus reflexos na temática do controle jurisdicional de políticas públicas. Em decorrência disso a pesquisa fragmenta-se em três partes: a primeira reserva-se a analisar os instrumentos de controle de constitucionalidade adotados pela Constituição Federal de 1988; a segunda trata de alguns aspectos ligados ao conceito de políticas públicas na seara política e na seara jurídica, bem como a tentativa de aproximação; a terceira, a relação do Supremo Tribunal Federal e o controle de políticas públicas no Brasil. Ao final, segue-se a conclusão.

\section{O controle de constitucionalidade e seu desenvolvimento histórico no Brasil}

O controle de constitucionalidade das leis pelos tribunais é uma criação do final do século XIX no Brasil. A Constituição de 1824 (Constituição do Império) não continha dispositivos legais acerca do controle da validade das normas jurídicas pelos tribunais, portanto cabia à Assembleia Geral velar pela guarda da Constituição, conforme o art. 15, IX da Constituição do Império. Segundo Heck, esse dispositivo era complementado pelo art. 173 da mesma Constituição, que indicava a competência da Assembleia Geral para verificar a observância da Constituição, no início de suas sessões. Também não se pode perder de vista a presença do Poder Moderador, no art. 98 da Constituição do Império (HECK, 2002).

O modelo adotado pela Constituição de 1891, após a proclamação da República em 15 de novembro de 1889, é o norte-americano. Com isso, introduz-se no Brasil o controle difuso presente no art. 59, $\S 1^{0}$ da Constituição, dispositivo que já estava presente na Constituição provisória de 1890 , no art. 58, $\S 1^{\circ}$. A Constituição de 1934 apenas deu continuidade ao desenvolvimento do controle associando à palavra recurso o adjetivo extraordinário, disposição contida no art. 59, § 10 da Constituição de 1891, reproduzida no art. 76, inc. III da Constituição de 1934. Ademais, introduz algumas modificações, relatadas por Heck: a) a declaração de inconstitucionalidade só poderia se dar por maioria absoluta de votos dos 
juízes dos tribunais (art. 179); b) a suspensão, por parte do Senado Federal, da execução de lei ou ato declarado inconstitucional (art. 91, inc. IV); e c) a introdução da representação interventiva do Procurador Geral da República (art. 12, § $2^{\circ}$ ).

Com a Constituição de 1937 opera-se uma restrição ao controle de constitucionalidade. Ela acolhe o art. 179 da Constituição de 1934, mas substitui a expressão Poder Público por ato do Presidente da República (art. 96, caput da Constituição de 1937). A cooperação com o Senado Federal é suprimida e, em seu lugar, é colocado Parlamento ou Presidente da República. Por outro lado, a representação interventiva não recebeu guarida na Constituição de 1937 (HECK, 2002, p. 60). A ampliação do controle veio com a Constituição de 1946, onde o controle difuso tinha sua previsão no art. 101, inc. III. A regulação prevista no art. 179 da Constituição de 1934 foi acolhida no art. 200 da Constituição de 1946. O previsto no art. 91, IV estava presente no art. 64 da Constituição de 1946. A grande inovação da Constituição da 1946 veio com a Emenda Constitucional (EC) no 16 de 06 de dezembro de 1956 que introduziu o controle concentrado direto no direito constitucional brasileiro. A modificação se deu no art. 101, inc. I, alínea "k" que dizia: "a representação contra inconstitucionalidade de lei ou ato de natureza normativa federal ou estadual, encaminhada pelo Procurador-Geral da República" deveria ser julgada pelo Supremo Tribunal Federal (HECK, 2002, p. $60)$.

Com a Constituição de 1967, que entrou em vigor no dia 15 de março de 1967, o controle difuso foi regulado no seu art. 114, III, quanto à maioria absoluta de votos para declarar a inconstitucionalidade (art. 179 da Constituição de 1934 e art. 200 da Constituição de 1946) foi acolhida no art. 111. Quanto à prescrição prevista no art. 91, IV da Constituição de 1934 e art. 64 da Constituição de 1946, relativa à suspensão de execução de lei ou ato declarado inconstitucional, estava presente no art. 45, IV da Constituição de 1967. No tocante à representação interventiva do Procurador-Geral da República, o art. 11, § 10 da Constituição de 1967 contemplou essa possibilidade.

Com a Emenda Constitucional no 1 de 17 de outubro de 1969 praticamente cria-se uma nova Constituição. No art. 119, III ficou previsto o controle difuso. A questão atinente ao voto da maioria nos tribunais para a declaração de inconstitucionalidade (art. 179 da Constituição de 1934, art. 200 da Constituição de 1946 e art. 111 da Constituição de 1967) inicialmente acolhido pelo art. $116 \mathrm{com}$ a EC no 1/69, recebeu uma modificação com a EC no 7/77. Por sua vez, o art. 42, VII incorporou as disposições previstas no art. 91, IV da Constituição de 1934 e no art. 45, IV da Constituição de 1967 (suspensão pelo Senado Federal da execução de ato ou de lei declarado inconstitucional). Ademais, o controle concentrado de constitucionalidade tinha sua previsão no art. 119, inc. I, alínea "I", com uma nova formulação (HECK, 2002).

Por fim, a Constituição de 1988 estipulou o controle por meio da ação direta de inconstitucionalidade no art. 102, inc. I, alínea "a" que, por 
oportunidade da Emenda Constitucional no 3, de 17 de março de 1993, introduziu ao lado da ação direta de inconstitucionalidade (ADIn), a ação declaratória de constitucionalidade (ADC). Por meio da citada Emenda Constitucional, também foi incluída a arguição de descumprimento de preceito fundamental (ADPF) presente no art. 102, § $1^{\circ}$ da Constituição de 1988. Em relação ao controle de constitucionalidade difuso, no art. 102, inc. III, alíneas "a", "b", "c" e "d", está a previsão do recurso extraordinário. Sobre a suspensão de lei ou ato declarado inconstitucional pelo Senado Federal está no art. 52, inc. $X$ da Constituição de 1988, reproduzindo as disposições previstas no art. 91, IV da Constituição de 1934, no art. 45, IV da Constituição de 1967 e no art. 42, inc. VII da Emenda Constitucional no 1 de 17 de outubro de 1969. Além disso, o art. 97 da Constituição de 1988 incorporou a disposição do art. 179 da Constituição de 1934, art. 200 da Constituição de 1946, art. 111 da Constituição de 1967 e art. 116 com a EC no $1 / 69$.

Como relatado inicialmente, quanto à ação direta de inconstitucionalidade e a ação declaratória de constitucionalidade, elas foram reguladas pela Lei no 9.868, de 10 de novembro de 1999; quanto à arguição de descumprimento de preceito fundamental, foi regulada pela Lei no 9.882 de 03 de dezembro de 1999. Essas breves linhas buscaram apresentar como se dá o desenvolvimento histórico do controle de constitucionalidade no Brasil. Parte-se de um momento em que não havia um controle da constitucionalidade das normas por meio de um tribunal, passando pela criação de um tribunal inspirado no modelo norte-americano de controle de constitucionalidade das leis e, pouco a pouco, importando a tradição de um modelo de controle abstrato do controle de constitucionalidade das leis. Portanto, importam-se modelos de controle de constitucionalidade sem um apreço pela sua adequação às instituições jurídico-políticas brasileiras, o que dificultou a compreensão e a consolidação delas. Isso fica evidenciado até mesmo pela dificuldade em relação a identidade do Supremo Tribunal Federal, entre um Tribunal Constitucional efetivamente ou um Tribunal ordinário.

A despeito dessas considerações, é inegável a importância da jurisdição constitucional na afirmação dos direitos fundamentais - mormente os direitos sociais - e também sua contribuição como instrumento voltado à garantia da Constituição, em última instância garantia das políticas públicas. O problema decorrente é quais são os limites de intervenção, no controle de constitucionalidade, em relação a juízos políticos em matéria de políticas públicas e como as referidas importações geraram descaminhos na definição dos papeis dessas instituições.

É preciso estar ciente que a própria existência do controle de constitucionalidade funda-se na tarefa de guardar a constituição, colocada na Constituição Federal de 1988 no art. 102, caput. A expressão guarda da constituição, de outra maneira, remete ao debate realizado nos anos 1930, entre Hans Kelsen (KELSEN, 2007b) e Carl Schmitt (SCHMITT, 2007). Schmitt localiza no monarca a ideia de órgão supremo do exercício do poder estatal, porém neutro e capaz de realizar sozinho o controle de constitucionalidade do 
exercício do poder estatal. Embasado na doutrina de Benjamin Constant, Kelsen aporta a crítica no trabalho intelectual ideologizado a que estava a serviço a tese de Constant, a qual tentava aduzir acerca do poder ideologicamente neutro do monarca constitucional (KELSEN, 2007a; HECK, 2008). Questiona como poderia ser o monarca, ou seja, detentor de grande parcela do poder estatal porta-se como instância neutra no exercício desse poder e, ainda, a única com vocação para o controle de sua constitucionalidade (KELSEN, 2007a). Dentro do contexto da atmosfera política da monarquia, colocar o monarca como guardião da Constituição serviria plenamente para atingir seus objetivos políticos, em que pese isso não representar a tarefa do fazer uma teoria constitucional.

Para isso, Schmitt vai de encontro à ideia de uma jurisdição constitucional (HECK, 1995), isto é, da existência de um tribunal independente responsável pela garantia de constitucionalidade das leis. Um tribunal responsável por julgar a constitucionalidade de atos do parlamento, de regulamentos, de leis, de atos do governo, cassando tais atos em caso de sua anticonstitucionalidade (HECK, 2008). Segundo Kelsen, os argumentos de Schmitt partem da oposição fundamental entre a função de justiça e a função política que particularmente a decisão sobre a constitucionalidade de leis e a anulação de leis anticonstitucionais é um ato 'político', do que é deduzido que tal atividade não é mais justiça (HECK, 2008). O político é visto na decisão (HECK, 2008) de conflitos de interesse, logo em toda a decisão judicial há um fator de exercício de poder, sendo mais forte o caráter político da justiça, na medida em que é dado uma maior amplitude ao poder discricionário (HECK, 2008; ALEXY, 2000; MAURER, 2006). Ou seja, a função judicial tem o mesmo caráter político que a dação de leis, porque há uma transferência de poder de criação do direito, em conformidade com essa discricionariedade. Logo, a distinção entre o caráter político da dação de leis e a justiça é somente quantitativa (HECK, 2008).

Essa relação que Schmitt traça entre a justiça caracterizando como dação de leis, preservando uma ideia de relação entre ambas as funções, não deixa a jurisdição constitucional valer como justiça. Schmitt conclui que, para conflitos e questões altamente políticas, o guarda da constituição não deve ser um tribunal, pois a justiça seria posta em perigo em função de sua politização (HECK, 2008 e 2006). Com isso, Schmitt reforça a ideia do poder para o controle de constitucionalidade, em outras palavras, a guarda da Constituição ficar em mãos do presidente do Império.

Isso demonstra a necessidade (moderna) da rigorosíssima separação entre o conhecimento científico e sentenças de valor político. Também o próprio reforço ao que estava sustentado na Constituição de Weimar tratou a própria história de mostrar o quão nefastos podem ser os resultados de tal esforço.

De outro lado, Kelsen posta-se como o defensor do Tribunal Constitucional como uma garantia constitucional. A jurisdição constitucional é vista como um sistema de medidas técnicas que garantem o exercício regular das funções estatais. Essa funções que, por sua vez, possuem um caráter 
jurídico, ou seja, consistem em atos jurídicos (normas jurídicas, atos de execução do direito criado). Em função disso, dividem-se as funções estatais entre legislação e execução que, via de regra, opõem-se enquanto dois momentos distintos: criação/produção do direito versus aplicação do direito. Por isso, a execução regular, sua conformidade com a lei, são o objeto próprio desse controle (KELSEN, 2007a). É caractere do Estado moderno a criação de leis, de regulamentos, da Constituição como etapas de formação da vontade coletiva estatal. Como a Constituição regula a criação de leis e de regulamentos (em observância à Constituição), a aplicação do direito (sentença, ato administrativo), da mesma maneira, deve se dar em observação à Constituição. Figuras definidas assim por Kelsen: "Estes, por sua vez, são aplicação do direito, se olharmos para cima, e criação do direito, se olharmos para baixo, isto é, no que concerne aos atos pelos quais são executados" (KELSEN, 2007a, p. 125).

Do ato de criação até 0 ato de execução, o direito não para de concretizar a Constituição, seja por normas jurídicas gerais (leis, regulamentos), seja por normas jurídicas individualizadas (sentença, ato administrativo), embora a liberdade de conformação do legislador em face da Constituição seja maior do que a reservada ao aplicador. Em outras palavras, a parte de aplicação aumenta enquanto a da livre criação diminui (KELSEN, 2007a). Desta maneira, a produção do direito, numa ordem jurídica, deve se dar respeitando o grau inferior e uma reprodução do direito com respeito ao grau superior. Cada grau aplica uma ideia que Kelsen chama de regularidade, isto é, a correspondência de um grau inferior com um grau superior de uma ordem jurídica. Isso não se aplica apenas às normas jurídicas individuais, que dão execução às leis, aos regulamentos, mas também às normas jurídicas gerais (leis, regulamentos). Ao definir a garantia da constitucionalidade das leis, Kelsen a define assim "Garantias da Constituição significam portanto garantias de regularidades das regras [graus jurídicos] imediatamente subordinadas à Constituição" (KELSEN, 2007a, p. 126-127), próprio da ideia da estrutura hierárquica do direito.

Para garantir essa regularidade é preciso, no entanto, que o judiciário fique responsável pelo julgamento, sendo que o órgão legislativo não é responsável pela aplicação do direito, considera-se, em realidade, livre para a criação do direito (vinculado pela Constituição). Desta forma, não é com o Parlamento que se conta para efetuar sua subordinação à Constituição. Há a necessidade de um órgão independente dele, diferente dele e de qualquer outra autoridade estatal, encarregado da anulação dos atos inconstitucionais, ou seja, um tribunal constitucional e, consequentemente, uma jurisdição constitucional. Esse tribunal, por outro lado, na lição de Kelsen, não está em oposição à soberania do Parlamento, isso porque a soberania não é do Parlamento, mas da ordem estatal (KELSEN, 2007a).

Assim, a Constituição é responsável por regular o processo legislativo, bem como as leis que regulam os procedimentos dos tribunais e das autoridades administrativas. Toda a regularidade, tanto do legislativo como da administração, tem uma vinculação à Constituição. De tal sorte que se conclui 
que o postulado da constitucionalidade das leis segue a mesma senda, teórica e tecnicamente, do que o postulado da legalidade da jurisdição e da legalidade da administração (KELSEN, 2007b). Cabe ainda tratar de outra objeção à existência de um tribunal responsável pelo controle de constitucionalidade, qual seja a violação do princípio da separação dos poderes. Sem dúvida a anulação (nulificação) de um ato legislativo por um órgão que não seja ele próprio será uma interferência no seu poder. Contudo, essa questão ganha novos traços ao percebermos que o órgão a que "é confiada a anulação das leis inconstitucionais não exerce uma função verdadeiramente jurisdicional, mesmo se, com a independência de seus membros, é organizado em forma de tribunal" (KELSEN, 2007a, p. 151). Anular a lei inconstitucional significa criar a lei com um sinal negativo, podendo isso ser interpretado como uma intromissão no poder legislativo.

Por essa perspectiva, o fato do Parlamento poder elaborar leis, decretos e regulamentos, conjuntamente com 0 Poder Executivo, representaria a violação do princípio da separação dos poderes. Ou mesmo, ter-se-ia que se estudar os motivos políticos da elaboração dessa doutrina com vistas à manutenção do equilíbrio constitucional. Entretanto, basta perceber que a manutenção do tribunal constitucional é melhor compreendida pela expressão "divisão dos poderes", isto é, a divisão de poderes entre órgão não pensando em os isolar, porém para permitir um controle recíproco de uns sobre os outros. Isso impede a concentração de poder nas mãos de um só órgão, e também garante a regularidade do funcionamento dos diferentes órgãos. Conclui, desta maneira, Kelsen: "Mas então a instituição da jurisdição constitucional não se acha em contradição com o princípio da separação dos poderes; ao contrário, é uma afirmação dele" (KELSEN, 2007a, p. 152).

A partir desses argumentos se tem a justificação à existência do controle de constitucionalidade por um tribunal constitucional, construção teórica de Hans Kelsen, a qual é da década de 1930. Com isso, buscou-se apresentar nesta parte a justificação da existência do controle de constitucionalidade e o desenvolvimento histórico dos instrumentos de controle de constitucionalidade nas diferentes Constituições brasileiras. Como se pode notar, cada um desses instrumentos de controle de constitucionalidade adotados pela Constituição brasileira e aportados pela doutrina de Hans Kelsen apontam no sentido de que o Supremo Tribunal Federal (STF), em que pese possua um poder discricionário para decidir, isto é, tenha um grau de liberdade dentro do quadro normativo constitucional, não se trata de um poder discricional ilimitado. Além disso, o enquadramento constitucional das políticas públicas gera o dever de revisar a constitucionalidade dessas caso o processo de uma política pública não esteja de acordo com a Constituição.

A dificuldade que surge, nesse desiderato, é que o Supremo Tribunal Federal brasileiro não faz apenas as vezes de um tribunal constitucional pois, como visto, não realiza o controle de constitucionalidade tão-somente de maneira concentrada (modelo preconizado por Kelsen), também trabalha na perspectiva do controle difuso (modelo norte-americano), duas importações 
distintas: uma com caráter de isenção política (Kelsen) e outra com caráter de politização do STF (norte-americano). Ambas geram dificuldade em delinear uma identidade, que é fundamental para compreender os limites de intervenção em termos de políticas públicas. É fulcral ressalvar que, nos dois casos, há uma franca importação de modelos, inclusive em relação aos debates que fundamentaram tais vertentes teóricas.

Todavia, como se observou, a justiciabiliadade dos direitos fundamentais sociais e, portanto, das políticas públicas deve ter uma decisão judicial (quando possível for o controle) amparada na Constituição. Ao contrário do Poder Executivo e do Legislativo que, pelo próprio caráter de suas atividades, possuem um grau maior de discricionariedade na elaboração e execução de políticas públicas. Daí a importância do controle de constitucionalidade e da própria relação com sua natureza para que se compreenda o porquê da necessidade de limitar tal controle e quais os parâmetros (critérios) fundamentais de intervenção do Judiciário no controle das políticas públicas. Diante disso, verificar-se-á a relação conceitual das políticas públicas com o direito e a ciência política, tendo em vista a necessidade de, num primeiro momento, apresentar a simplificação que é feita, em termos de ciência jurídica, e, em segundo lugar, o espaço de atuação política - apresentado pela ciência política - que é importante para a compreensão e a manutenção da estrutura de poderes, bem como da identificação do papel da jurisdição constitucional e limites em políticas públicas.

\section{As políticas públicas, sua relação com o direito e a possibilidade do controle judicial}

Para se chegar ao controle judicial das políticas públicas no Brasil é preciso antes compreender em que consistem as políticas públicas e qual a sua relação com a ciência jurídica, mais especificamente com o direito administrativo. De posse de tais pressupostos conceituais, propõe-se a necessidade do controle judicial e a necessária participação do Poder Judiciário na conformação constitucional das políticas públicas.

Inegável o crescimento dos estudos na área das políticas públicas no Brasil, principalmente nas pesquisas ligadas à ciência política. Especificamente no Brasil essas pesquisas ganham maior importância a partir dos anos 1980 (ARRETCHE, 2003; SOUZA, 2006). Diferentemente, na ciência jurídica as pesquisas ligadas às políticas públicas e sua relação com o controle judicial tiverem um crescimento recente, nos Programas de Pós-Graduação em Direito, na última década tema que antes ficava adstrito tão somente ao chamado controle do ato administrativo discricionário sem maiores delineamentos conceituais (GARCIA, 2009). Esse abismo entre as duas ciências gerou consequências nefastas para ambas.

De um lado, em geral (COUTO, 2005), os trabalhos ligados à ciência política abandonam a questão ligada à conformação constitucional e, por outro, a ciência jurídica propõe, em alguns casos, uma espécie de grau zero 
de discricionariedade, como se não houvesse um espaço para a política na elaboração de políticas públicas. Daí a necessidade de se elaborar um conceito que fosse capaz de conformar as duas áreas do conhecimento. Os enfoques dados às políticas públicas foram prioritariamente da ciência política, da sociologia, da economia política, da ciência, da administração e da filosofia política, ficando num segundo plano a análise estritamente jurídica das políticas públicas (GARCIA, 2009).

Isso porque, a despeito de uma política pública ficar vinculada à Constituição e, consequentemente, às leis, aos regulamentos, às ordens advindas do poder legislativo, há um espaço de conformação do governo, porém, dentro do quadro normativo proposto pela Constituição (KELSEN, 2006). No entanto, há fenômenos que ocorrem no âmbito do Estado e que merecem uma particular análise por parte da ciência jurídica e que, todavia, projetam-se nas políticas públicas como a monitoração, a regulação e a avaliação dos resultados das políticas públicas (GARCIA, 2009). Tais fenômenos não se ajustam perfeitamente aos quadros tradicionais do pensamento jurídico, porém merecem atenção por parte da ciência jurídica por não terem uma clara autonomia.

Para a ciência política não existe uma definição única de política pública, por algum tempo considerou-se as políticas públicas exclusivamente como outputs do sistema político, focando o interesse dos pesquisadores nas demandas e articulações de interesses políticos (inputs) (FARIA, 2003). Em outras palavras, as políticas públicas e sua análise eram vistas como uma subárea da disciplina. Seu estudo, portanto recaía na depuração da formação das políticas públicas dando um status privilegiado para os processos políticos decisórios, em uma análise eastoniana (EASTON, 1965). Hoje há uma enorme diversidade de abordagens e teorizações dos processos de formação e gestão das políticas públicas (FARIA, 2003). Para além disso, dependendo, na ciência política, dependendo do modelo adotado de política pública há uma forma de analisar a política pública e, da mesma forma, um conceito diferente (DYE, 2009).

No campo das abordagens há a teoria sistêmica (David Easton), o funcionalismo estrutural (Gabriel Almond) e o ciclo da política. Também, no campo dos modelos de quem faz políticas públicas há teoria de grupo (Robert Dahl), teoria de elite (Wright Mills), corporativismo (Philippe Schmitter) e subgovernos (Hugh Heclo). Por fim, os tipos de políticas públicas, como a tipologia clássica de Theodor Lowi (regulatória, distributiva ou redistributiva), política material ou simbólica (Murray Edelman), políticas substancial ou procedimental (James Anderson) e políticas de bens coletivos ou bens privados (Michael O'Hare) (THEODOULOU, 1995). Como se pode observar, há todo um processo de tradução do conhecimento em matéria de políticas públicas que é fulcral ao Direito nesta etapa de Estado Democrático de Direito, um conhecimento que data do início do século XX (LASSWELL, 1950).

O modelo mais conhecido (DYE, 2009; RODRIGUES, 2010) e importado pela ciência jurídica é o chamado institucionalismo, que coloca as instituições governamentais como centro das atenções das políticas públicas. Tal modelo 
estuda a relação entre políticas públicas e as atividades governamentais (envolvendo o Executivo, o Legislativo e o Judiciário). Por meio das instituições governamentais empresta-se legitimidade e universalidade às políticas públicas. Em outras palavras, as políticas públicas, nesse modelo, cobram legalidade e, portanto, cumprimento por parte dos responsáveis e atingem todas as pessoas da sociedade, independentemente do grupo que por ventura pertençam. Por fim, o terceiro caractere desse modelo é a coercibilidade, dito de outra forma, cabe ao próprio governo fazer cumprir as políticas públicas, não havendo sanções por parte de outros grupos sociais, monopólio estatal (DYE, 2009).

É com base nesse modelo que se aborda a possibilidade do controle judicial das políticas públicas, a partir da ciência política. Até pelo papel que exerce o modelo institucional na sua origem, pois é fruto da ciência política norte-americana dentro, assim, dos freios e contrapesos constitucionais, passíveis de controle judicial. Outro importante modelo para a ciência jurídica é o que identifica a política pública como um processo. Isso porque permite mostrar todos os processos político-administrativos, identificando o processo político como uma série de atividades (identificação de problemas, organização de agenda, formulação, legitimação, implementação e avaliação). $\mathrm{Na}$ leitura de Theodoulou (1995) esse processo poderia ser fracionado da seguinte forma: a) reconhecimento do problema e identificação das temáticas envolvidas naquela mesma área de atuação, em outros segmentos da Administração Pública, que possam contribuir para favorecer ou bloquear as soluções; b) inserção do tema na agenda de ação do poder público; c) formulação da política pública a ser concretizada, traduzindo-se concretamente as ações; d) adoção da política pública, não só edição de ato, mobilização de órgãos e adoção de medidas necessárias; e) implementação da política, envolvendo ações concretas por parte dos órgãos administrativos envolvidos; f) análise da avaliação da política pública executada, à vista dos parâmetros que originalmente pautaram a sua concepção.

No entanto, todo esse processo realizado pelas instituições não se dá descolado de marcos normativos, ou melhor, descolado da constitucionalidade dessas políticas públicas. A figura das políticas públicas, no âmbito jurídico, surge como uma forma de concretização dos chamados direitos sociais, fruto de transformação do Estado liberal operada no século XX. Exigem-se prestações positivas do Estado com os chamados direitos sociais, apresentando-se no universo jurídico as políticas públicas.

Por sua vez, para a ciência jurídica, as políticas públicas são definidas como standard que tem um objetivo social, econômico e político a ser atingido, fruto de uma conformação com o ordenamento jurídicoconstitucional, ou seja, as políticas públicas implicam em um dever de realização por parte de todos os poderes estatais e não apenas do poder executivo ou de determinado governo, diferentemente do dito em relação à ciência política, a política pública para a ciência jurídica assume uma feição finalística. A política pública envolve todos da atividade estatal e não apenas o governo. Embora a política pública fique vinculada à Constituição e, 


\section{DOSSIÊ DEMOCRACIA E POLÍTICAS PÚBLICAS}

consequentemente, às leis, aos regulamentos, às ordens advindas do poder legislativo, há um espaço de conformação do governo, porém, dentro do quadro normativo proposto pela Constituição (KELSEN, 2006). Logo, a política pública é acompanhada de ações visando a realização de seus objetivos, uma vez que os objetivos estão insertos na política pública. Por fim, a política pública é um ato contínuo, isso significa dizer que não é apenas o ato que decreta uma lei (em conformidade com o estabelecido na Constituição Federal), mas também os atos subsequentes de implementação, execução e avaliação. Todos esses atos devem ser feitos em conformidade com a Constituição (THEODOULOU, 1995).

Isso significa dizer que dentro do quadro normativo dado pela Constituição, em alguns aspectos a política pública autoriza uma conformação política, por sua própria natureza de processo político-administrativo, todavia a escolha feita pelo governante ou administrador público deve ser realizada de tal forma que seja possível ser justificada argumentativamente e, portanto, racionalmente. Assim, não se pode aduzir que uma eventual decisão administrativa, seja na formação ou seja na implementação de políticas públicas não sofra limite algum e fique ao alvedrio de um determinado aspecto político-partidário. Mesmo programas partidários devem estar em consonância com a Constituição Federal servindo, nesse caso, de limite, ou mesmo de contenção a programas que não se identifiquem com ela. Por isso, pode-se dizer que a política pública é condicionada pela política competitiva (conflito, cooperação, alianças entre os diversos atores políticos), mas acima dela há a política constitucional (define a própria estruturação do Estado e sua normatização, isto é, a Constituição) (COUTO, 2005). Nesse sentido, é próprio do texto constitucional fixar os limites da política atuando no papel de proteção negativa, ou seja, impedindo que políticas públicas sejam simplesmente condicionadas por maiorias parlamentares ou tampouco pelo simples alvedrio do administrador público, impondo a fundamentação de quaisquer decisões (HECK, 1995).

Da mesma forma, ao tratar da inconstitucionalidade de atos realizados pelo executivo, durante o estado de sítio, na incipiente República brasileira deveriam ser anulados em decorrência de sua não conformação. Ruy Barbosa (BARBOSA, s/d) argue que os tribunais teriam autoridade para negar a execução do decreto e manter o direito dos indivíduos, quando fosse submetida a demanda à autoridade da justiça, sendo esse direito de examinar a inconstitucionalidade dos atos legislativos ou administrativos a base do regime constitucional. Embora a obra de Ruy Barbosa não se ocupe e, tampouco, existissem no Brasil estudos acerca de políticas públicas, quanto ao seu controle judicial deve ser desenvolvida a mesma esteira de argumentos, não sendo possível a existência de políticas públicas que não estejam de acordo com a ordenação constitucional. Para tanto, essa primeira aproximação entre ciência política e ciência jurídica tem como objetivo demonstrar que o conceito o qual se aporta a ciência jurídica é extremamente limitado, pois é finalístico. Nessa perspectiva, é preciso estabelecer um diálogo com a ciência política, a qual apresenta a complexidade e as 
implicações relativas às políticas públicas, no entanto sempre atentando aos diferenciais metodológicos no processo de análise.

As políticas públicas são muitas e diversificadas, há desde a concretização de opções constitucionais básicas, que são responsáveis por definirem em um plano primário a ação estatal, caracterizadas por sua transversalidade e por sua globalidade, como referido anteriormente, enquanto caractere geral das políticas públicas; há, da mesma maneira, as micro-políticas, que são regionalizadas. Não obstante, mesmo as políticas públicas setoriais ou regionalizadas são consequências da primeira espécie de política públicas - a qual se poderia denominar macro-políticas (GARCIA, 2009). Ainda, é possível distinguir, conforme a área geográfica das entidades públicas internas com que os cidadãos se relacionam, as políticas públicas locais que são ligadas à esfera Municipal; as políticas públicas estaduais que são vinculadas aos Estados-Membros e as política públicas federais que têm como ente responsável a União. Não se pode olvidar que, em função do Direito Comunitário, hoje também é possível falar em políticas públicas mundiais ou políticas públicas supranacionais (no caso de país signatário de tratado ou acordo) (GARCIA, 2009).

Em todas essas espécies uma ideia-chave une todas as políticas, qual seja a sua dimensão jurídica, isto é, todas as políticas públicas encontram desde logo a Constituição Federal como seu alicerce fundamental. Ou no caso de políticas públicas advindas do Direito Comunitário ou do Direito Internacional no caso da permissividade a acordos e tratados internacionais por meio do monismo jurídico (KELSEN, 2006). Portanto, a lei formal, por si, não permite averiguar a validade das políticas públicas, é mister ir além e buscar na Constituição o seu ato instituidor por excelência. Por conseguinte, o Estado, seu Governo e a Administração Pública devem atuar fazendo uso da racionalidade argumentativa, fundamentando passo-a-passo a eleição de determinada política pública, não devendo esses agentes estatais apenas atuarem apelando à racionalidade subsuntiva. É preciso uma ampla combinação

entre meios disponíveis, vias de acção e intencionalidades que, num amplo processo argumentativo, em situação, conduzido pelos princípios de direitos convocados pela acção as soluções são encontradas (GARCIA, 2009, p. 57-58).

Desta forma é necessária a fundamentação (justificação) pela Administração Pública para a elaboração das políticas públicas. É necessário responder argumentativamente, a partir do plano constitucional. Em não sendo assim, cabe ao Poder Judiciário intervir determinando a correção da política pública que seja inconstitucional fazendo assim com que a Administração tenha uma política pública em conformidade com a Constituição Federal. É preciso salientar que a resposta dada pelo Judiciário também deve ser legítima sob a ótica argumentativa. Para que se possa compreender como se dá essa resposta constitucional com base na 
argumentação é preciso, por outro lado, compreender todo o processo de formação de bases teóricas, modelos e atores envolvidos nas políticas públicas. Diante disso, apresenta-se a possibilidade de diálogo entre ciência jurídica e ciência política, pela superação do conceito finalístico de políticas públicas na ciência jurídica. Como se poderá observar a seguir, essa formatação finalística, influenciada - principalmente - por Ronald Dworkin (1999) gerará incorreções relativas ao controle de constitucionalidade no Brasil.

\section{O controle de constitucionalidade de políticas públicas no Brasil}

Antes de se tratar do controle de políticas públicas no Brasil, é preciso compreender o que se entende por políticas públicas a partir de um aporte que permita mesclar elementos da ciência jurídica e da ciência política, por uma novo entendimento em relação ao controle jurisdicional das políticas públicas. O ponto de partida adotado para a compreensão do conceito de políticas públicas é a distinção realizada por Ronald Dworkin (1977, 1999, 1995) entre principle (princípio) e policy (políticas públicas). No seu Los derechos en Serio ao tratar do modelo de regras I (model of rules $I$ ) abre sub-capítulo destinado à distinção entre regras (rules), princípios (principles) e políticas públicas (policies). Assim, propõe-se a utilização do termo princípio, genericamente, para se referir para todo grupo de standards de conduta os quais não se adequem dentre as regras. Entretanto, é possível ser mais preciso e estabelecer a distinção entre princípios (principles) e políticas públicas (policy). Uma policy é entendida, para Dworkin (1999), um tipo de standard que estabelece um objetivo a ser alcançado. Em geral representa um melhoramento com caracteres sociais ou econômicos da comunidade. Princípio (principle), por sua vez, é um standard para ser observado, não porque sua observância represente um avanço ou um assegurar uma situação política, social ou econômica desejada, mas por ser uma requisição de justiça ou equidade ou outra dimensão de moralidade (DWORKIN, 1977 e 1999).

A política pública envolve todos os ramos da atividade estatal e não apenas o governo, embora fique vinculada à Constituição e, consequentemente, às leis, aos regulamentos, às ordens advindas do poder legislativo, há um espaço de conformação do governo, porém dentro do quadro normativo proposto pela Constituição. Logo, a política pública é acompanhada de ações visando a realização de seus objetivos, não havendo a cisão entre diretriz e políticas públicas, uma vez que os objetivos estão insertos na política pública. Por fim, a política pública é um ato contínuo, isso significa dizer que não é apenas o ato que decreta uma lei (em conformidade com o estabelecido na Constituição Federal), mas também os atos subsequentes de implementação, execução e avaliação. Todos esses atos devem ser feitos em conformidade com a Constituição (THEODOULOU, 1995). O processo de elaboração à execução de determinada política pública deverá respeitar, nessa perspectiva, o proposto pelo art. 30 da Constituição Federal de 1988. Dessa forma, o Estado deve traçar uma série de medidas voltadas à 
coletividade (ordem pública), com o intuito de concretizar um direito voltado à comunidade.

Desta maneira, não se pode resumir as políticas públicas tão-somente ao ato de implementação dessa e à sua finalidade (afirmação de direitos sociais), pois há um processo que tem início com a escolha realizada pelo legislador, dentro do quadro normativo, culminando com a formulação realizada pela Administração Pública e com a adoção de atos necessários à execução de determinada política pública. Da mesma forma, nesse processo, há o acompanhamento do Poder Judiciário que verificará a adequação entre o standard preconizado como objetivo social, político ou econômico previsto na Constituição Federal e aquilo que o Estado propõe enquanto ação para realizar essa política pública. Isso, de certa maneira, permite afirmar que há a possibilidade de controle dessas políticas públicas por parte do Judiciário, principalmente ao verificar a constitucionalidade das políticas públicas. Uma margem de conformação ilimitada, novamente, autorizaria a confusão entre uma política partidária e uma política pública. Com isso, propõe-se a superação da confusão, do ponto de vista conceitual, isto é: por um lado temos a liberdade de determinada agremiação política (partido político) eleger uma política - corporificada numa política de governo - e, ao ocupar o Executivo, buscar a sua adequação aos parâmetros constitucionais das políticas públicas; de outro, há o processo de criação, execução e implementação de políticas públicas que envolvem todo o Estado, ou seja, Poder Legislativo, Poder Executivo, Poder Judiciário intentando a concretização do previsto na Constituição Federal (BUCCI, 2002, 2006 e 1996).

A possibilidade de submeter uma política pública ao controle judicial é, também, inquestionável, tendo em vista que a Constituição Federal garante no art. 50, inc. XXXV, o direito ameaçado ou lesado. Entretanto, ao tratar da resposta ou de como os juízes devem responder há uma diferença substancial. A política pública em seu processo de formulação e de execução se dá com base em argumentos de política, isto é, um argumento que justifique uma decisão política demonstrando que essa decisão avança ou protege alguns objetivos coletivos da comunidade como um todo, dentro do espectro (margem) apresentado pela Constituição Federal. A Constituição institui os bens valiosos a serem conservados (direitos fundamentais), por exemplo, direito à saúde previsto no art. 198 da Constituição Federal, essa base jurídica é o ponto de partida à adequação política. Dessa forma, partindo-se da Constituição (argumento de princípio - argumento jurídico) procurar-se-á estabelecer a política pública com base em argumentos de política.

Quando uma política pública desvia-se em relação ao direito fundamental a ser tutelado, fica evidenciada a sua inconstitucionalidade. Seria o caso, por exemplo, do Executivo e do Legislativo não formularem políticas públicas de saúde, a despeito da previsão constitucional. Esse caso, na nomenclatura de Dworkin (1999), pode ser chamado de um caso fácil, pois a omissão geraria uma inconstitucionalidade, devendo o Judiciário intervir em 
matéria de políticas públicas. O cuidado ocorre e, portanto, o ponto onde o diálogo entre ciência jurídica e política torna-se fundamental é quando questiona-se a adequação de uma determinada política pública em relação ao enquadramento constitucional. Ou seja, na mesma perspectiva, seria o caso em que se questiona, por exemplo, o porquê de adotar determinada política de saúde voltada à prevenção (saúde familiar) e não ampliar o número de hospitais, esse é um caso que se pode chamar de difícil, conforme Dworkin (1999).

Assim, propõe-se a tese que as decisões nos casos difíceis devem ser geradas caracteristicamente por princípios e não por decisões baseadas em argumentos de política. Em outras palavras, para que o juiz chegue à conclusão em determinado caso relacionado a políticas públicas, é preciso que haja argumentos que justifiquem a eleição daquele direito em detrimento de outro e, além disso, que essa decisão abra a perspectiva de sua universalização (caractere essencial de uma decisão judicial, tendo em vista a variedade de decisões judiciais que temos no Brasil sem um cuidado em relação a sua fundamentação jurídica). Os juízes não devem fundar suas decisões em argumentos de política (DWORKIN, 2000). Para Dworkin (1999), mesmo nos casos difíceis, os juízes devem apelar para os argumentos de princípio, e não argumentos de política. Se os juízes fossem convocados a decidir conforme argumentos de política o risco para a liberdade individual seria maior, certamente, do que se as decisões fossem a favor da proteção da moral e dos direitos políticos dos cidadãos de sua comunidade. Por conseguinte, o risco que surge nesse caso é de que a liberdade individual restaria erodida a um patamar maior do que o processo político, na primeira espécie de decisão. Na segunda hipótese, o risco é que os juízes sejam conservadores e se valham de seu poder menos que poderiam, negando-se a reconhecer direitos individuais que o processo político haja consolidado no direito positivo (DWORKIN, 1999).

Para isso, Dworkin (1999) encontra a solução no que chama de juiz Hércules, uma metáfora utilizada pelo autor para tratar de um juiz dotado de capacidades extraordinárias, capacitado para reconstruir, com coerência, em cada caso, o direito vigente, para que possa ser tomada a melhor decisão possível amparada em argumentos de princípios. Com o intuito de garantir a correção do direito, apresenta uma reconstrução racional e coerente do mesmo. Ao juiz Hércules caberá definir os argumentos de princípio que suportam o precedente, assim definirá a força gravitacional do precedente. 0 precedente é fundamental para que o juiz escreva o que ele chama de romance em cadeia, isto é, como na literatura os precedentes são como capítulos de livros e é preciso saber o argumento do capítulo anterior para que não se perca em coerência, em relação ao texto. Hércules deverá saber reconhecer que na sua comunidade é reconhecido que as decisões judiciais devem ser tomadas utilizando por base argumentos de princípios, a despeito de argumentos de política (DWORKIN, 1995).

Ainda para Dworkin (2000) há duas espécies de interpretações possíveis quando se busca conjugar a lei à Constituição. Em primeiro lugar 
seria a busca da intenção original do legislador e, a partir disso, tentar conformar todas as decisões com a intenção original do legislador, do constituinte originário. Assim, a cada decisão caberia ao juiz reconstituir a vontade do criador da Constituição em relação ao texto constituição, adequando essa ao texto que estivesse, por ventura, em discussão à citada vontade. No entanto, nem os legisladores, nem os componentes da Suprema Corte Norte-Americana, tampouco os cidadãos conseguem chegar a um termo sobre qual a vontade dos criadores da Constituição, mormente, se as questões estiverem ligadas a pontos politicamente polêmicos. Em segundo lugar, outros enfocam, para Dworkin (2000), entre questões substanciais e procedimentais, cabendo ao controle de constitucionalidade o tocante a questões ligadas ao procedimento, sem ingressar em questões constitucionais substanciais. Ou seja, ao juiz não cabe rever se a escolha dos legisladores, politicamente, foi justa (substantivamente), mas apenas se os legisladores observaram os procedimentos. Importando para a hipótese de trabalho aqui esposada, ao juiz só caberia rever se a política pública eleita pelo legislador e proposta pelo Executivo observou as formas procedimentais, não cabendo intervir quanto ao conteúdo pois, presumidamente, aqueles que ocupam esse espaço atuam sob a salvaguarda da Constituição. Quanto ao primeiro argumento, seria o papel do juiz remontar a vontade dos criadores da Constituição para saber se os termos propostos pela política pública estariam adequados, ou melhor, em conformidade com a Constituição. Ocorre que, nessa segunda hipótese, como aventou Dworkin (2000), incorre-se em um dilema democrático, isso porque se tornaria competência do juiz interpretar decisões tomadas pelos criadores, o que, logicamente, dá abertura a um maior poder discricional e afasta o julgador de uma decisão apolítica.

Ambos os argumentos falham pois eles incorporam apenas a faceta substantiva, eles dizem o que deve ser deixado ao povo. Para Dworkin, cabe ao julgador tomar decisões de princípios e não decisões de política, "[...] decisions about what rights people have under our constitutional system rather than decisions about how the general welfare is best promoted [...]" (DWORKIN, 2000, p. 69) ${ }^{1}$. Deve-se partir do princípio de que todos os cidadãos são iguais. Por conseguinte, vislumbra-se um julgamento sob princípios e não sob política, em que o julgador não despose de sua visão política ao decidir, mas fundamente sua decisão em argumentos, em que o argumento de maior força gravitacional será preponderante. Nessa perspectiva, o controle judicial de políticas públicas deve ser sustentado mas a decisão, em se tratando de intervir em políticas públicas, deve ser justificada (fundamentada) por argumentos - tanto a decisão do administrador público quanto eventualmente a decisão do Poder Judiciário. $\mathrm{Na}$ revisão da conformidade de uma política pública com a Constituição não deve haver espaço para uma decisão política por parte do juiz, reduzindo assim a sua discricionariedade judicial. Mesmo o administrador tem a sua

\footnotetext{
1 "decisões sobre quais direitos o povo tem dentro do sistema constitucional do que decisão sobre como o bem-estar geral será melhor promovido" (tradução nossa).
} 


\section{DOSSIÊ DEMOCRACIA E POLÍTICAS PÚBLICAS}

discricionariedade reduzida, podendo adequar um plano político-partidário, desde que em conformidade (e fundamentado) com a Constituição.

Com base nisso, aventa-se a possibilidade do julgador encontrar o que a chamada resposta correta (DWORKIN, 1995), nos casos difíceis, o que não significa uma resposta correta, tendo em vista que não raro os juízes errarão (DWORKIN, 1995). Cabe ao juiz, por meio de nexos argumentativos, encontrar respostas qualitativamente adequadas à materialidade da Constituição Federal. Com isso, se dá as traves fundamentais ao controle de políticas públicas. Seguir na senda de decisões que careçam de justificação, ou apenas sejam calcadas em ementários jurisprudenciais ou princípios, sem a adequada fundamentação em argumentos de princípio, dá ensejo a decisões comprometidas com ideologias partidárias e outros tipos de compromissos políticos, nefastos ao controle judicial das políticas públicas e ao próprio conceito de políticas públicas. Por isso, o conhecimento de todo o processo de formulação das políticas públicas, no âmbito político-administrativo, é importante para a decisão, não cingindo o julgador a questões finalísticas em termos de políticas públicas. Não pode, nesse sentido, haver abertura ao arbítrio dos juízes, pois uma política pública deve estar adequada à Constituição Federal.

\section{Conclusão}

A pesquisa buscou apresentar, dentro das limitações de um trabalho deste fôlego, os caminhos e descaminhos do controle de constitucionalidade de leis no Brasil e as diferentes importações adotadas, ou seja, de como um modelo de controle de constitucionalidade adotado e a contribuição do controle de constitucionalidade no Brasil à compreensão da possibilidade e da necessidade do controle judicial das políticas públicas. No entanto, demonstrando que esse controle de constitucionalidade das políticas públicas não pode ocorrer de forma ilimitada, sendo preeminente a racionalidade, sob a ótica argumentativa, das decisões judiciais. Por outro lado, a pesquisa buscou entrelaçar melhor a ideia de políticas públicas para a ciência jurídica e para a ciência política, tendo em vista que esse entrelaçamento entre política e política constitucional representa uma medida adequada ao controle judicial das políticas públicas.

Para isso, na primeira parte apresentou-se o desenvolvimento histórico, do ponto de vista normativo, em relação ao controle de constitucionalidade de leis no Brasil e quais instrumentos de controle de constitucionalidade dispõe-se atualmente. Ademais, buscou-se demonstrar como se dão os debates em relação à guarda precípua da Constituição, ou seja, o debate entre Hans Kelsen e Carl Schmitt, principalmente, a crítica que Kelsen faz em relação à politização do debate, por parte de Schmitt. Também, como Schmitt instrumentaliza ou permite a instrumentalização da jurisdição constitucional. Kelsen posta-se como o defensor do Tribunal Constitucional como uma garantia constitucional, a jurisdição constitucional é vista como um sistema de medidas técnicas que garantem o exercício regular das funções 
estatais. Essas funções que, por sua vez, possuem um caráter jurídico, ou seja, consistem em atos jurídicos (normas jurídicas, atos de execução do direito criado).

Após isso, buscou-se demonstrar as peculiaridades das políticas públicas sob a ótica conceitual e de como a política pública, ou melhor, as políticas públicas têm uma profunda relação com a necessidade que tais sejam conformadas com o previsto na Constituição. Observa-se, a despeito disso, que as pesquisas com o foco na ciência política deixam escapar, em geral, o aspecto ligado à constitucionalidade das políticas públicas e, todavia, a ciência jurídica quando se ocupa das políticas públicas recorre a conceitos que tratam as políticas públicas como discricionariedade administrativa, sem que as políticas públicas possuam um grau de autonomia nos estudos realizados na ciência jurídica. Além disso, muitas vezes, olvida-se o espaço político de conformação das políticas públicas - na ciência jurídica - e a necessidade que as políticas públicas estejam em conformidade com os parâmetros constitucionais - conforme a ciência política. Assim, mister uma conjugação desses dois aspectos. Ou mesmo, dos modelos de análise de políticas públicas.

A necessidade da conformação desses dois aspectos gerou consequentemente que o observar as políticas públicas sob a ótica constitucional adquirisse novos foros e, portanto, ao Judiciário coubesse verificar se a política pública atende o previsto na Constituição Federal. Destarte, gera-se a necessidade do Poder Judiciário de controlar as políticas públicas, superando-se o dogma de que essas (por seu caráter político próprio) seriam insindicáveis pelo Poder Judiciário. Por fim, apresentou-se a discussão acerca do controle de constitucionalidade das políticas públicas no Brasil, bem como da própria importação do conceito de políticas públicas e de como esses descaminhos, em função dessas importações, saca um debate, 0 qual deveria ser realizado no bojo da ciência jurídica para o campo político.

Isso reflete diretamente no controle da constitucionalidade das políticas públicas, ficando as decisões, muitas vezes, ao alvedrio do juízo político do julgador do que a reconstrução, do ponto de vista argumentativo, da sua decisão, buscando a racionalização da decisão. Para tanto, baseou-se na em alguns pressupostos teóricos tratados, principalmente, por Ronald Dworkin. Portanto, em conformidade com as dimensões de uma pesquisa dessa natureza, demonstrou-se a possibilidade do controle judicial das políticas públicas, sob a ótica da ciência jurídica, a despeito das considerações na seara da ciência política. Depois, apresentaram-se aquelas, para fins desse trabalho, as mais importantes influências em termos de controle argumentativo da decisão judicial em matéria de políticas públicas.

Hector Cury Soares é Doutorando em Direito pela Universidade Federal do Rio Grande do Sul (UFRGS). Mestre em Direito pela Universidade do Vale do Rio dos Sinos (UNISINOS). Professor Assistente da Universidade Federal do Pampa (UNIPAMPA) na área de Administração Pública.

E-mail: hectorcury@gmail.com 


\section{Referências}

ALEXY, Robert. Vício no exercício do poder discricionário. Trad. Luís Afonso Heck. Revista dos Tribunais, São Paulo, v. 779, n. 91, p. 33-51, 2000.

ARRETCHE, Marta. Dossiê Agenda de Pesquisa em Políticas Públicas. Revista Brasileira de Ciências Sociais, São Paulo, v. 18, n. 51, p. 7-9, fev. 2003.

BARBOSA, Ruy. A Constituição e os Actos Inconstitucionais do Congresso e do Executivo ante a Justiça Federal. 2. ed. Rio de Janeiro: Atlântida, s./d.

BRASIL. Constituição do Império (1824). Disponível em: <http://www.planalt o.gov.br/ccivil_03/Constituicao/Constituiçao24.htm>. Acesso em: 05 jul. 2010.

. Constituição de 1891. Disponível em: <http://www.planalto.gov.br/c civil_03/constituicao/Constitui\%C3\%A7ao91.htm>. Acesso em: 05 jul. 2010.

. Constituição de 1934. Disponível em: <http://www.planalto.gov.br/c civil_03/constituicao/Constitui\%C3\%A7ao34.htm>. Acesso em: 05 jul. 2010.

. Constituição dos Estados Unidos do Brasil (1937). Disponível em: <http://www.planalto.gov.br/ccivil_03/constituicao/constitui\%C3\%A7ao37.ht m>. Acesso em: 13 ago. 2012.

. Constituição de 1946. Disponível em: <http://www.planalto.gov.br/c civil_03/constituicao/Constituiçao46.htm>. Acesso em: 06 jul. 2010.

. Constituição da República Federativa do Brasil de 1967. Disponível em: <http://www.planalto.gov.br/ccivil_03/constituicao/Constitui\%C3\%A7ao 67.htm>. Acesso em: 13 ago. 2012.

. Constituição da República Federativa do Brasil de 1988. Disponível em: <http://www.planalto.gov.br/ccivil_03/constituicao/constitui\%C3\%A7ao. htm>. Acesso em: $28 \mathrm{dez} .2010$.

BUCCI, Maria Paula Dallari. As Políticas Públicas e o Direito Administrativo. Revista Trimestral de Direito Público, São Paulo, n. 13, p. 134-144, 1996.

. Direito Administrativo e Políticas Públicas. São Paulo: Saraiva, 2002.

(Org.). Políticas Públicas: reflexões sobre o conceito jurídico. São Paulo: Saraiva, 2006. 
COUTO, Cláudio Gonçalves. Constituição, Competição e Políticas Públicas. Lua Nova, São Paulo, n. 65, p. 95-135, maio-ago. 2005.

DWORKIN, Ronald. Is Law a System of Rules? In: DWORKIN, Ronald. The Philosophy of Law. Londres: Oxford Press, 1977. p. 43-44. . Los Derechos en serio. Barcelona: Ariel, 1995.

Universty Taking Rigths Seriously. Cambridge/Massachusetts: Harvard . A matter of principle. Cambridge/Massachusettes/London: Harvard University Press, 2000.

DYE, Thomas R. Mapameamento dos modelos de análise de políticas públicas. In: HEIDEMANN, Francisco; SALM, José Francisco (Orgs.). Políticas Públicas e Desenvolvimento - bases epistemológicas e modelos de análise. Brasília: UnB, 2009. p. 99-101.

EASTON, David. A Framework for Political Analysis. Englewood Cliffs: Prince Hall, 1965.

FARIA, Carlos Aurélio Pimenta de. Idéias, Conhecimento e Políticas Públicas. Um inventário sucinto das principais vertentes analíticas recentes. Revista Brasileira de Ciências Sociais, São Paulo, v. 18, n. 51, p. 21-29, fev. 2003.

GARCIA, Maria da Glória Ferreira Pinto Dias. O Direito das Políticas Públicas. Coimbra: Almedina, 2009.

HECK, Luís Afonso. O Tribunal Constitucional Federal e o Desenvolvimento dos Princípios Constitucionais: contributo para uma compreensão da Jurisdição Constitucional Alemã. Porto Alegre: Sérgio Antonio Fabris, 1995.

. O Controle Normativo no Direito Constitucional Brasileiro. Revista dos Tribunais, São Paulo, ano 91, v. 800, p. 57-64, jun. 2002.

(Trad.). Jurisdição Constitucional e Legislação Pertinente no Direito Comparado. Porto Alegre: Livraria do Advogado, 2006.

- Jurisdição Constitucional: teoria da nulidade versus teoria da nulificabilidade das leis. Porto Alegre: Livraria do Advogado, 2008.

KELSEN, Hans. Teoria Pura do Direito. Trad. João Baptista Machado. São Paulo: Martins Fontes, 2006. 
A Jurisdição Constitucional (Exposição de Hans Kelsen). In: KELSEN, Hans (Org.). Jurisdição Constitucional. Trad. Maria Ermantina de Almeida Prado Galvão. São Paulo: Martins Fontes, 2007a. p. 121-186.

. Quem deve ser o guardião da Constituição? In: KELSEN, Hans (Org.). Jurisdição Constitucional. Trad. Alexandre Krug. São Paulo: Martins Fontes, 2007b. p. 237-298.

LASSWELL, Harold D. Politics: Who gets What, When, How. New York: Peter Smith, 1950.

MAURER, Hartmut. Direito Administrativo Geral. Trad. Luís Afonso Heck. São Paulo: Manole, 2006.

PESSOA, Fernando. Odes de Ricardo Reis: obra poética III. Porto Alegre: L\&PM, 2008.

RODRIGUES, Marta M. Assumpção. Políticas Públicas. São Paulo: Publifolha, 2010.

SCHMITT, Carl. O guardião da Constituição. Trad. Geraldo de Carvalho. Belo Horizonte: Del Rey, 2007.

SOUZA, Celina. Políticas Públicas: uma revisão da literatura. Sociologias, Porto Alegre, ano 8, n. 16, p. 20-45, jun.-dez. 2006.

THEODOULOU, Stella Z. The Nature of Public Policy. In: CAHN, Matthew A.; THEODOULOU, Stella Z. (Orgs.). Public Policy: the essential readings. New Jersey: Prentince-Hall, 1995. p. 1-10.

Texto recebido em 26/02/2012.

Aprovado em 20/07/2012. 